\title{
The impact of surgery-first approach on the oral health-related quality of life: a systematic review and meta-analysis
}

\author{
Xinqi Huang ${ }^{1,2}$, Xiao Cen ${ }^{1,3}$, Wentian Sun ${ }^{1,2}$, Kai Xia ${ }^{1,2}$, Liyuan Yu ${ }^{1,2}$, Jun Liu ${ }^{1,2^{*}}$ (D) and Zhihe Zhao ${ }^{1,2^{*}}$
}

\begin{abstract}
Background: The oral health-related quality of life (OHRQoL) is affected by dentofacial deformity. Patients with dentofacial deformity are normally treated with orthognathic surgery, including conventional three-stage method (CTM) and surgery first approach (SFA). The aim of this systematic review and meta-analysis was to compare the impact of SFA with CTM on the OHRQoL of patients with severe dentofacial deformity.
\end{abstract}

Methods: Five English databases, three Chinese databases, and six grey literature databases were searched (January 2000 to July 2018). Randomized controlled trials, controlled clinical trials, and cohort studies assessing the OHRQoL of patients who underwent SFA or CTM were included. After selecting studies, extracting data, and assessing risk-ofbias according to the Cochrane Handbook for Systematic Reviews of Interventions and the Newcastle-Ottawa Scale, meta-analysis was performed to elucidate the effects of SFA on the changes of OHRQoL of patients with dentofacial deformity at each stage and made a comparison with CTM.

Results: There were 4 studies with 122 participants were selected for the final analysis. Three among these studies were included in meta-analysis, 2 of which were included in each forest plot. All the included studies were graded as moderate value of evidence according to GRADE quality analysis. Over the period of 2-year follow-up after bonding, the OHRQoL of the patients in SFA group showed an improving trend and was better than those in CTM group generally. After debonding, the summary scores of the 14-item Oral Health Impact Profile (OHIP-14) $(-2.92, P=0.12)$ and Orthognathic Quality of Life Questionnaire (OQLQ) $(-5.59, P=0.01)$ were smaller in SFA group than CTM group.

Conclusions: Clinical evidence indicates that SFA can contribute to the better OHRQoL in patients with dentofacial deformity immediately and persistently.

Keywords: Surgery-first approach, Dentofacial deformity, Oral health-related quality of life, Systematic review, Metaanalysis

\section{Background}

Oral health-related quality of life (OHRQoL) is a multidimensional construct reflecting the comfort of eating, sleeping, and engaging in social interaction, which measures the impact of oral health on emotion, society, and function of daily life [1]. Gender has shown to influence OHRQoL $[2,3]$. It is also reported that disadvantaged adolescents might experience poor OHRQoL due

\footnotetext{
* Correspondence: junliu@scu.edu.cn; zhzhao@scu.edu.cn

${ }^{1}$ State Key Laboratory of Oral Diseases \& National Clinical Research Center for Oral Diseases, West China Hospital of Stomatology, Sichuan University, No. 14, 3rd Section, South Renmin Road, Chengdu 610041, Sichuan, China Full list of author information is available at the end of the article
}

to the worse oral condition, which suggested socioeconomic position was an important factor of OHRQoL [4].

Dentofacial disharmonies are observed in $38.5 \%$ of adolescents $[5,6]$, which severely affect daily life such as breathing, speaking, and eating. These patients are also potentially with self-abasement and socially awkward, which afflicts psychosocial development [7-9]. Therefore, dentofacial deformities have seriously unfavorable influence on the patients' OHRQoL [10].

The conventional orthognathic surgery, also named as conventional three-stage method (CTM), generally consists of presurgical orthodontic treatment, surgery treatment, and postoperative orthodontic adjustment

(C) The Author(s). 2019 Open Access This article is distributed under the terms of the Creative Commons Attribution 4.0 International License (http://creativecommons.org/licenses/by/4.0/), which permits unrestricted use, distribution, and 
[11]. According to this protocol, presurgical orthodontic treatment, which is essential to the final stable surgical results, will focus on removing dental decompensation, aligning and leveling the teeth, and coordinating dental arches [12]. This process, however, can hardly contribute to the changes of vertical and transverse plane [13]. It was indicated that the correction of transverse discrepancy could be addressed with surgery without presurgical orthodontic treatment [14]. In addition, there are gingival recession, enamel decalcification, root resorption, and worsening lip profile during presurgical orthodontic treatment $[15,16]$. These results inevitably have a negative effect on the aesthetic and psychologic aspects. It was reported that the OHRQoL of patients in the presurgical orthodontic treatment was worse than that in the postsurgical treatment phase [17].

In 1988, Behrman raised the concept of "surgery first and orthodontics second", which was also named as surgery first approach (SFA) [18]. They hypothesized that once the jaw position was counterbalanced, the normalized soft tissues would facilitate the postoperative tooth movement, and thus shorten the duration of treatment. Clinical data from Chang Gung University also demonstrated that the surgical environment might bring about 4-month period of higher bone metabolic changes and osteoclastic activities, possibly accelerating postoperative tooth movement [19]. It was indicated that postoperative alignment was similar to that in Class I cases, and any possible surgical relapse could be rectified with postoperative orthodontics [20]. Based on this approach, a preplanned orthodontic treatment is fulfilled after the surgery, yielding promotion in the facial aesthetics straight away and providing a decreased total treatment time $[21,22]$. These components may lead to the enhancement of patients' cooperation and better OHRQoL $[23,24]$. A large curve of Spee, however, may hamper the accurate evaluation of a predictable mandible position and final occlusion, resulting in difficulties in designing treating plan [21]. It was also exhibited that the relapse rate of SFA group was higher than that of CTM $[25,26]$.

Previous systematic reviews mainly focused on the effectiveness of SFA [13, 27-30]. Only one of them suggested that the immediate improvement in facial esthetics might have a positive influence on OHRQoL roughly, which only described two studies on this aspect and did not involve the relevant results of different periods or perform the quantitative synthesis [29].

In this systematic review and meta-analysis, we searched the literatures, evaluated the quality of clinical trials, and summed up the evidence to elucidate the effects of SFA on the changes of OHRQoL of patients with dentofacial deformity at each stage and made a comparison with CTM.

\section{Methods}

\section{Protocol and registration}

This systematic review protocol was registered under the PROSPERO register with the number CRD42018099063 (www.crd.york.ac.uk/prospero).

\section{Eligibility criteria}

Only full-length articles, which satisfied following criteria based on PICOS schema, were considered for inclusion in this systematic review.

1. Patients (P): all participants, with no restriction on age, gender, or malocclusion types.

2. The intervention group (I): SFA.

3. The control group (C): CTM.

4. Types of outcome measurements $(\mathrm{O})$ : OHRQoL, with no filter for the instruments.

5. Study types (S): prospective and retrospective studies including randomized clinical trials (RCTs), controlled clinical trials (CCTs), and cohort studies.

\section{Exclusion criteria}

1. Intervention without orthognathic surgery.

2. Outcomes without data on OHRQoL.

3. Repetitive publication.

\section{Information sources and search strategy}

Two calibrated reviewers (X.H. and X.C.) conducted the electronic searches independently, and any disagreements were solved by discussion or judged by the third reviewer (J.L.).

Five English databases (i.e. Cochrane Database of Systematic Reviews, the Cochrane Central Register of Controlled Trials, PubMed, Embase, and Medline (via Ovid)), three Chinese databases (i.e. China National Knowledge Infrastructure, Chinese Biomedical Literature Database, and VIP Database), and six grey literature databases (EOS abstract index, IADR abstract index, clinicaltrials.gov, ISRCTN registry, Grey Literature Report, and Open Grey) were searched from January 2000 to July 2018 (updated to July 2018), with no language restrictions. We also checked the reference lists of the included studies to guarantee the inclusion of all relevant studies. The details of the Medline (via Ovid) search were shown in Table 1.

\section{Selection of studies}

Two calibrated reviewers (X.H. and X.C.) checked the titles and abstracts of the identified records and screened out obviously irrelevant ones, and then evaluated full text reports for potentially suitable studies, independently and in duplicate. 
Table 1 Details of Medline (via Ovid) search

1. exp. "Quality of Life"/
2. QoL.mp.
3. OHRQoL.mp.
4. oral health-related quality of life.mp.
5. 1 or 2 or 3 or 4
6. Orthognathic Surgery/
7. surgery first approach.mp.
8. exp. Orthognathic Surgical Procedures/
9. surgery first.mp.
10. 6 or 7 or 8 or 9
11. 5 and 10

If supplemental information was required, these two reviewers would contact the corresponding author of the study and this study would be categorized as awaiting assessment. Any disagreement was judged by two adjudicating senior authors (J.L. and Z.Z).

\section{Data extraction}

Two of the authors (W.S and K.X) extracted and recorded the data independently. Two adjudicating senior authors (J.L. and Z.Z) resolved the referred disagreement.

The source and nationality of participants, treatment types, follow-up periods, and outcome measurements were recorded. The participants information also included gender, number, and malocclusion types. The follow-up periods were classified into after bonding, after surgery, and debonding. The outcomes were the scores of OHRQoL, which could be measured by different kinds of questionnaires, and information of the instruments was also extracted.

\section{Quality assessment}

Two reviewers (X.H. and X.C.) were calibrated and independently assessed the risk of bias of the included randomized trials by the Cochrane Handbook for Systematic Reviews of Interventions from six separate domains: random sequence generation; allocation concealment; blinding of participants and personnel; blinding of outcome assessment; incomplete outcome data; selective reporting [31].

For the nonrandomized studies, we judged the risk of bias with the Newcastle-Ottawa Scale and employed "star system". One study could be awarded one star for each numbered item when it fulfilled certain criteria, which was regarded as low risk of bias. When there was no description in the study, the risk of bias was regarded as unclear, while the other conditions were regarded as high risk of bias [32]. (Table 2).

Each study was graded with A, B, or C, based on the GRADE quality analysis criteria [33]. (Table 3).

\section{Meta-analysis and sensitive analysis}

It is nonsensical to combine the comparisons of different treatments with different comparators, or combine the diverse outcome measurements [34]. Therefore, a metaanalysis was planned to perform, when the comparisons of treatments and follow-ups were similar, and the instruments to measure OHRQoL were same.

For continuous data, mean difference and 95\% confidence intervals (CIs) would be used. The measurements of SFA effect for binary data were to be shown as relative risks along with 95\% CIs. The statistical significance was set at $\alpha=0.05$ (two tailed z tests) [35].

Statistical heterogeneity was tested by the chi square and $\mathrm{I}^{2}$ tests [36]. If heterogeneity was high $\left(\mathrm{I}^{2}>50 \%\right)$, the random-effects model was selected for the meta-analysis. Otherwise, the fixed-effects model was chosen [36].

Sensitivity analysis would be conducted to explore the possible source of heterogeneity. The "leave one out" approach, when more than two studies were included, was planned to evaluate the effect of each study on the summary risk.

Table 2 Items and criteria of the Newcastle-Ottawa scale for quality assessment

\begin{tabular}{lll}
\hline & Items & When to give stars (low risk of bias) \\
\hline Selection & Representativeness of the exposed cohort & truly or somewhat representative of the average in the community \\
& Selection of the control group & Drawn from the same community as the exposed cohort \\
& Ascertainment of the treatment group & Secure record or structured interview \\
& Demonstration that outcome of interest was not & Yes \\
& present at start of study & \\
Comparability & Comparability of participants on the basis of the design & Study controls for the most important factor or any additional factor \\
& or analysis & \\
Autcome & Assessment of outcome & Independent blind assessment or record linkage \\
& Was follow-up long enough for outcomes to occur? & Yes \\
& Adequacy of follow-up & Complete follow-up, or Subjects lost to follow-up unlikely to introduce bias, \\
& & or small number lost follow-up, or description provided of those lost
\end{tabular}


Table 3 Criteria of GRADE quality analysis

\begin{tabular}{ll}
\hline Definitive grade & Criteria \\
\hline $\begin{array}{l}\text { Grade A } \\
\text { (high value) }\end{array}$ & Randomized clinical study or a prospective study \\
& with a well-defined control group; \\
& Clear definition of diagnosis and endpoints; \\
& $\begin{array}{l}\text { Description of diagnostic reliability tests and } \\
\text { reproducibility tests; }\end{array}$ \\
& Blinding of outcome assessment. \\
& Cohort study or retrospective study with \\
Grade B & a well-defined control group; \\
& Clear definition of diagnosis and endpoints; \\
& Description of diagnostic reliability tests and \\
& reproducibility tests. \\
Grade C & Large attrition; \\
(low value) & Unclear definition of diagnosis and endpoints; \\
& Ill-defined patient material. \\
\hline
\end{tabular}

\section{Results}

Study selection

Four studies, including 122 participants (59 subjects for SFA and 63 subjects for CTM) published between 2015 and 2017, were included in the final analysis [37-40]. The references of these studies were examined, but yielded no studies for evaluation. The flow diagram is shown in Fig. 1.

\section{Study characteristics}

The characteristics of eligible studies are presented in Table 4. One of included study was retrospective nonRCT [37], while two studies were prospective non-RCTs $[38,39]$ and the other one study was prospective RCT [40]. Three studies enrolled skeletal Class III patients [37-39], while the other one studied the patients with skeletal Class III and II malocclusion [40]. All of them were treated with SFA or CTM. One study employed Orthognathic Quality of Life Questionnaire (OQLQ)

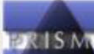

PRISMA 2009 Flow Diagram

.
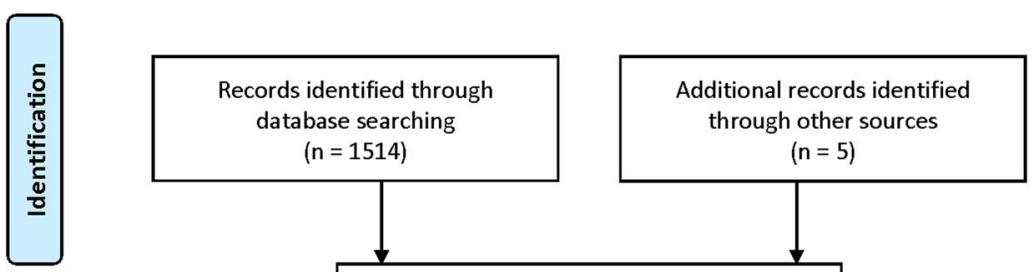
$n=1514)$

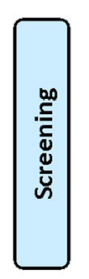

Records after duplicates removed

$(n=1441)$
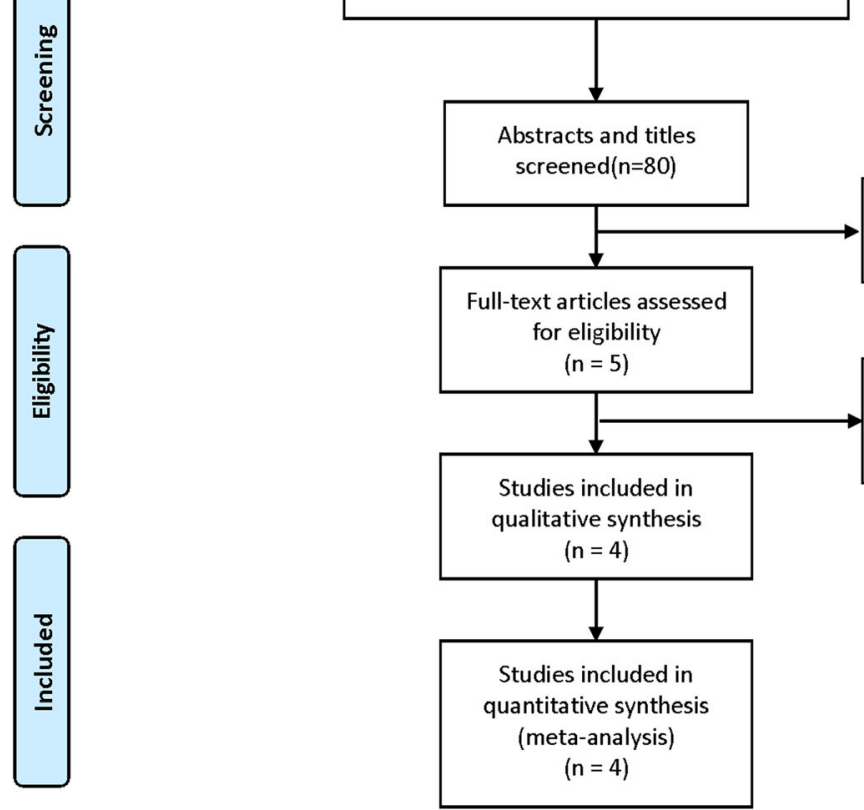

Fig. 1 Flow of information through the different phases of the systematic review 
Table 4 Characteristics of the included studies

\begin{tabular}{|c|c|c|c|c|c|c|c|}
\hline Study & Country & Institution & $\begin{array}{l}\text { Participants } \\
(\mathrm{N})\end{array}$ & $\begin{array}{l}\text { type of } \\
\text { malocclusion }\end{array}$ & Outcomes & $\begin{array}{l}\text { Follow-ups after } \\
\text { bonding }\end{array}$ & Follow-ups after surgery \\
\hline Park 2015 & Korea & Not reported & $\begin{array}{l}\text { SFA group: } \\
\text { 9F, } 2 \mathrm{M} \\
\text { CTM group: } \\
12 \mathrm{~F}, 3 \mathrm{M}\end{array}$ & $\begin{array}{l}\text { skeletal Class } \\
\text { III }\end{array}$ & OQLQ & - & $\begin{array}{l}3 \text { months, } \\
\text { debonding }\end{array}$ \\
\hline Huang 2016 & China & $\begin{array}{l}\text { Department of Orthodontic at } \\
\text { the Stomatology Hospital of } \\
\text { Wen Zhou Medical University }\end{array}$ & $\begin{array}{l}\text { SFA group: } \\
13 \mathrm{~F}, 12 \mathrm{M} \\
\text { CTM group: } \\
13 \mathrm{~F}, 12 \mathrm{M}\end{array}$ & $\begin{array}{l}\text { skeletal Class } \\
\text { III }\end{array}$ & OHIP-14 & $1,6,12,18$ months & $\begin{array}{l}\text { 1, } 6,12 \text { months, } \\
\text { debonding }\end{array}$ \\
\hline Feu 2017 & Brazil & Rio de Janeiro State University & $\begin{array}{l}\text { SFA group: } 8 \\
\text { CTM group: } 8\end{array}$ & $\begin{array}{l}\text { skeletal Class } \\
\text { III }\end{array}$ & $\begin{array}{l}\text { OQLQ, } \\
\text { OHIP-14 }\end{array}$ & $\begin{array}{l}1,3,6,12,24 \\
\text { months }\end{array}$ & - \\
\hline Pelo 2016 & Italy & $\begin{array}{l}\text { Department of Surgical Sciences } \\
\text { for Head and Neck Diseases at } \\
\text { Catholic University of Sacred Heart }\end{array}$ & $\begin{array}{l}\text { SFA group: } \\
15 \\
\text { CTM group: } \\
15\end{array}$ & $\begin{array}{l}\text { skeletal Class } \\
\|/\| \|\end{array}$ & $\begin{array}{l}\text { OQLQ, } \\
\text { OHIP-14 }\end{array}$ & - & $\begin{array}{l}1 \text { month, } \\
\text { debonding }\end{array}$ \\
\hline
\end{tabular}

Conventional Three-stage Method, CTM Surgery First Approach, SFA Number, N Female, F Male, M Orthognathic Quality of Life Questionnaire, OQLQ 14-item Oral Health Impact Profile, OHIP-14

[37], while another one study applied 14-item Oral Health Impact Profile (OHIP-14) [38] and the other two studies selected both of them as the OHRQoL questionnaires $[39,40]$. The follow-ups were classified into three kinds, namely after bonding, after surgery, and debonding.

\section{Quality assessment}

According to the GRADE quality analysis, all the included studies were graded as moderate value of evidence, i.e. Grade B (Table 5).

All the included studies lacked blinding of participants and personnel as well as outcome assessment (Figs. 2, 3) [37-40]. As the orthognathic surgery and orthodontic braces were evident, it is difficult to blind patients and clinicians.

There were no incomplete outcomes data and selective reporting in the prospective randomized clinical trial by Pelo et al., but this study did not mention the method of allocation concealment [40] (Fig. 2).

As for the three non-RCTs [37-39], the ascertainment of intervention was securely recorded. Participants in treatment group were comparable to those in control group [37, 38], except for the study of Feu et al. [39]. No drop-outs were found in the included studies [37-39]. In the study by Huang et al., the selection of participants was representative in the community [38]. However, all the non-RCTs did not mention the selection of control group [37-39] (Figs. 2, 3)
The scores of OHIP-14

In the study of Feu et al., there was significant difference between SFA group and CTM group at baseline, and two patients in SFA group accomplished surgery 3 months after their braces bonded while others in SFA group underwent surgery as soon as braces bonded [39]. These factors could result in unnegleted clinical heterogeneity, which made this study not meta-analyable. The scores of OHIP-14 in group CTM and group SFA at different time-points after bonding, which were reported by Huang et al. [38] and Feu et al. [39], were showed in Table 6.

At 1 month after bonding, Feu et al. reported 6 participants in SFA group have underwent orthognathic surgery, and the score of OHIP-14 in CTM group was smaller than that in SFA group $(P=0.16)$ [39]. However, all of 25 participants have underwent orthognathic surgery at this time-point in Huang et al., and it is showed that the score of OHIP-14 in SFA group was smaller significantly than that in CTM group $(P<0.001)$ [38].

When bonded for 6 months, the score of OHIP-14 in CTM group kept smaller than that in SFA group without significance $(p=0.49)$ in the study by Feu et al. [39], while Huang et al. reported the results in diverse direction that the SFA group showed smaller OHIP-14 score significantly $(P<0.001)$ [38].

At 12 months after bonding, the scores of OHIP-14 in both studies (by Feu et al. and by Huang et al.)

Table 5 Quality assessment

\begin{tabular}{|c|c|c|c|}
\hline Study & Study design & Study type & Definitive grade \\
\hline Park 2015 & Retrospective & Non-randomized controlled trial & B \\
\hline Huang 2016 & Prospective & Non-randomized controlled trial & B \\
\hline Feu 2017 & Prospective & Non-randomized controlled trial & $\mathrm{B}$ \\
\hline Pelo 2017 & Prospective & Randomized controlled trial & B \\
\hline
\end{tabular}




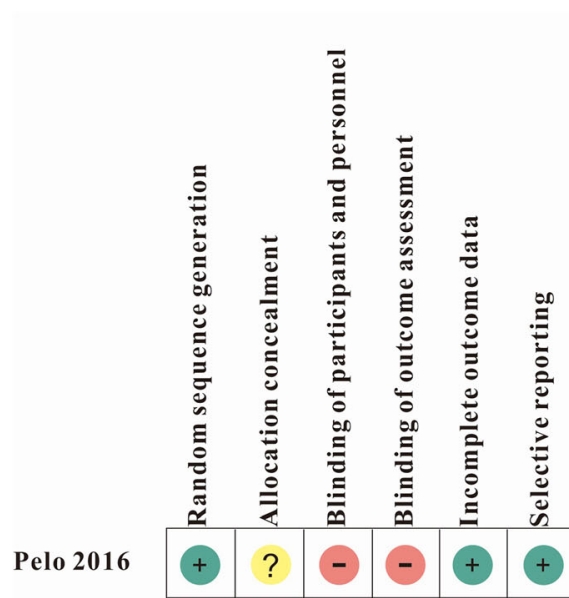

Low risk of bias

? Unclear risk of bias

Fig. 2 Risk of bias summary

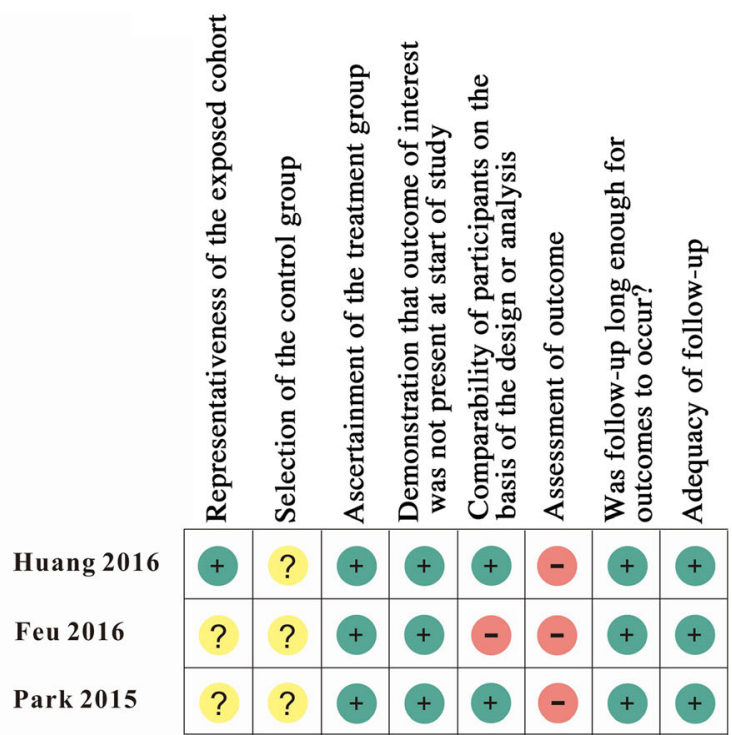

High risk of bias were smaller in SFA group than those in CTM group $(P=0.25$ and $P<0.001$, respectively) $[38,39]$.

On debonding, the scores of OHIP-14 were showed in two studies (Huang et al. and Pelo et al.) with 40 patients in SFA groups and 40 patients in CTM groups $[38,40]$, which were combined statistically in metaanalysis. The random effect model was selected as the heterogeneity was high $\left(\mathrm{I}^{2}=97 \%, P<0.001\right)$. The summary score of OHIP-14 in SFA group was 2.92 smaller without significance $(P=0.12)$ (Fig. 4$)$.

\section{The scores of OQLQ}

Over the period of 2-year follow-up after bonding, the OHRQoL of the patients in SFA group showed improvement generally. The score of OQLQ in SFA group was 6.1 at 1 year after bonding, which was much smaller than that in CTM group significantly $(P<0.01)$ [39]. When bonded for 2 years, the score of OQLQ in SFA group kept smaller than that in CTM group $(P<0.01)$ and 14.1 smaller than that at baseline $(P<0.01)[39]$.

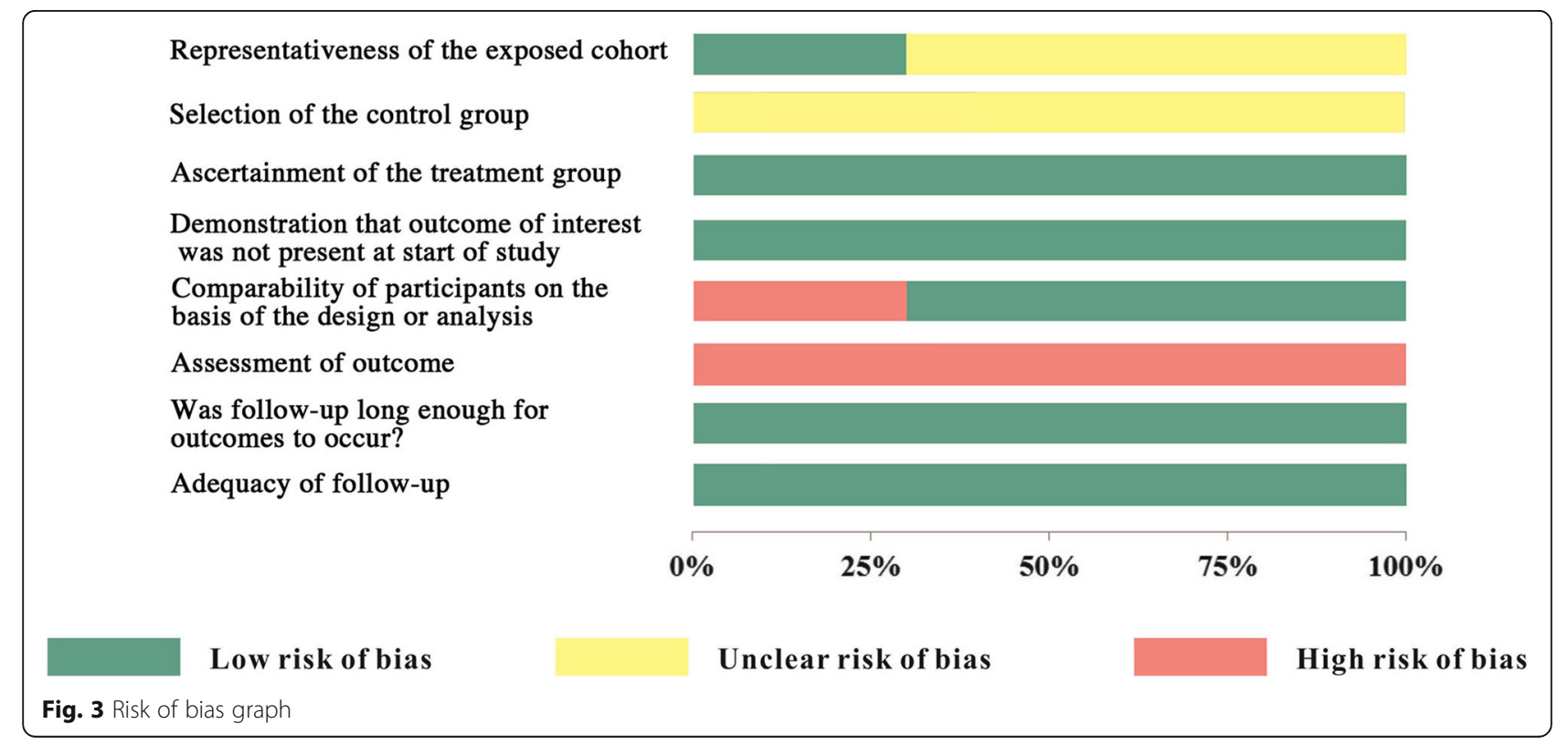


Table 6 The scores of OHIP-14 in group CTM and group SFA at different time-points after bonding

\begin{tabular}{lllllllll}
\hline & Intervention/number & Baseline & $1 \mathrm{~m}$ & $3 \mathrm{~m}$ & $6 \mathrm{~m}$ & $12 \mathrm{~m}$ & $18 \mathrm{~m}$ & $24 \mathrm{~m}$ \\
\hline Feu 2016 & SFA/8 & $25.4 \pm 5.6$ & $26.9 \pm 10.6$ & $17.0 \pm 9.7$ & $14.9 \pm 11.0$ & $7.5 \pm 6.6$ & not reported & $8.1 \pm 5.7$ \\
& CTM/8 & $21.5 \pm 9.0$ & $20.4 \pm 4.6$ & $15.0 \pm 6.7$ & $11.1 \pm 8.7$ & $14.1 \pm 11.3$ & not reported & $22.1 \pm 11.8$ \\
Huang 2016 & SFA/25 & $38.68 \pm 4.35$ & $27.72 \pm 3.26$ & not reported & $13.94 \pm 2.13$ & $6.9 \pm 1.39$ & $4.11 \pm 0.49$ & not reported \\
& CTM/25 & $39.55 \pm 4.15$ & $41.67 \pm 4.14$ & not reported & $48.48 \pm 3.91$ & $28.86 \pm 3.83$ & $15.61 \pm 2.49$ & not reported \\
\hline
\end{tabular}

When the brackets were debonded, the scores of OQLQ were reported in two studies (Park et al. and Pelo et al.) with 26 participants in the SFA groups and 30 participants in the CTM groups $[38,40]$, which were combined statistically in meta-analysis. The fixed effect model was selected for the low heterogeneity $\left(\mathrm{I}^{2}=37 \%\right.$, $P=0.21)$. The summary score of OQLQ in SFA group was 5.59 smaller significantly $(P=0.01)$ (Fig. 5$)$.

As there were only 2 studies included for each forest plot, it is hard to leave one out to explore the source of heterogeneity among studies.

\section{Discussion}

Facial esthetics has a vital influence on personal selfconfidence and interpersonal relationships, which drives the patients with dentofacial deformity to undergo orthognathic surgery [41-43]. CTM and SFA, two kinds of ortho-surgical treatments, are different in the treatment sequence, duration, patient compliance, and degree of patients' satisfaction, which could make OHRQoL widely divergent.

This systematic review was performed to compare the effect of SFA with CTM on the OHRQoL of patients. Although SFA has been used for more than a decade, only a few studies focused on this issue. For that reason, there were only 4 suitable articles to be included [37-40].

OHIP-14, a kind of self-rating questionnaires, is invented to assess the patients' OHRQoL. It contains 14 questions, which are divided into 7 sections, including functional limitation, physical pain, psychological discomfort, physical incapacity, psychological incapacity, social incapacity, and difficulty doing usual jobs [41]. As the reliability and validity of OHIP-14 have been tested in different countries and languages, it is utilized to describe patients' OHRQoL widely [44-46]. It was indicated a smaller score of OHIP-14 in SFA group than that in CTM group at 1 month after bonding [38]. This result can be owing to the fact that the patients in SFA group had finished the surgery and had facial profile improved immediately at this time-point, and SFA made the patients achieve similar degree of satisfaction and dentofacial harmony to those with normal skeletal relationship [47]. At the same time-point, the patients in CTM group were just at the beginning of presurgical orthodontics and had worse facial deformity as a result of dental decompensation by CTM. Anterior crossbite was reported to influence esthetics and mastication function negatively, which contributed to a worse OHRQoL during the presurgical orthodontic stage [48, 49]. It was also reported that $73.6 \%$ patients with dentofacial deformities were uncomfortable by their appearance and almost half of them felt functional limitations before surgery, and esthetic and functional domains of QoL were improved after surgery [50]. A contrary result, however, was demonstrated in the study by Feu et al. [39]. It might be due to the differences of both groups at baseline and only 6 of the patients in SFA group who had finished surgery at 1 month after bonding.

The OQLQ, developed by Cunningham, is another self-rating questionnaire invented to assess the patients' OHRQoL, and is also validated all around the world, especially in measuring the influence of dentofacial deformities and the benefits of orthognathic surgical treatment on patients' OHRQoL [51-53]. Over the period of 2-year follow-up after bonding, the OHRQoL of the patients in SFA group, which was measured by OQLQ, showed improvement generally and kept better than that in CTM group [39]. After debonding, the summary scores of OHIP-14 and OQLQ of the patients treated with SFA were smaller than CTM. These results might be contributed by side effects of the presurgical orthodontics of CTM such as white spot and periodontal

\begin{tabular}{|c|c|c|c|c|c|c|c|c|c|}
\hline \multirow[b]{2}{*}{ Study or Subgroup } & \multirow{2}{*}{ Mean } & \multicolumn{2}{|l|}{ SFA } & \multicolumn{2}{|c|}{ СтM } & \multirow[b]{2}{*}{ Total } & \multirow[b]{2}{*}{ Weight } & \multirow{2}{*}{$\begin{array}{l}\text { Mean Difference } \\
\text { IV, Random, } 95 \% \mathrm{CI}\end{array}$} & \multirow{2}{*}{$\begin{array}{l}\text { Mean Difference } \\
\text { IV, Random, } 95 \% \mathrm{CI}\end{array}$} \\
\hline & & SD & Total & Mean & SD & & & & \\
\hline Huang 2016 & 3.89 & 1.02 & 25 & 8.68 & 1.65 & 25 & $50.6 \%$ & $-4.79[-5.55,-4.03]$ & 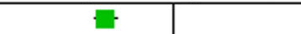 \\
\hline Pelo 2017 & 2 & 1 & 15 & 3 & 2 & 15 & $49.4 \%$ & $-1.00[-2.13,0.13]$ & - 맘 \\
\hline Total $(95 \% \mathrm{CI})$ & & & 40 & & & 40 & $100.0 \%$ & $-2.92[-6.63,0.79]$ & \\
\hline \multicolumn{9}{|c|}{$\begin{array}{l}\text { Heterogeneity. } \mathrm{Tau}^{2}=6.94 ; \mathrm{Chi}^{2}=29.69, \mathrm{df}=1(\mathrm{P}<0.00001) ; \mathrm{I}^{2}=97 \% \\
\text { Test for overall effect: } Z=1.54(\mathrm{P}=0.12)\end{array}$} & 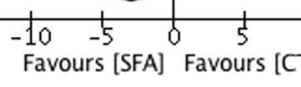 \\
\hline
\end{tabular}

Fig. 4 The summary score of OHIP-14 in the SFA group and the CTM group on debonding 


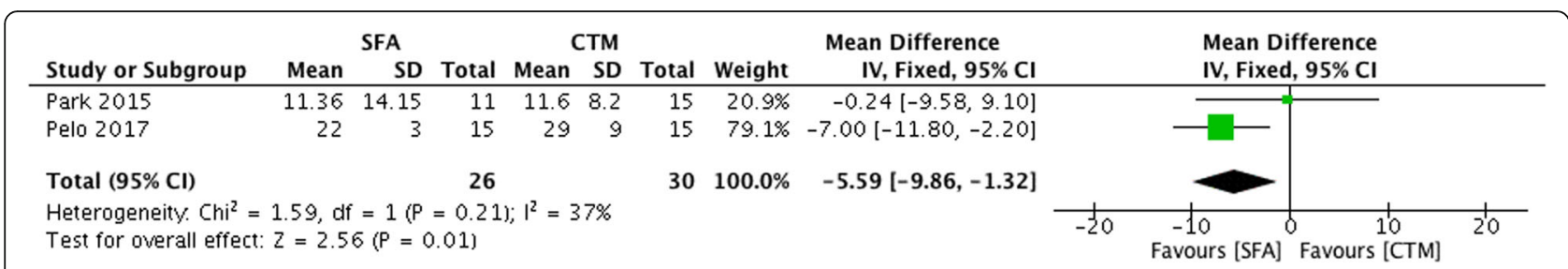

Fig. 5 The score of OQLQ in the SFA group and the CTM group when the brackets were debonded through fixed model

inflammation [54, 55], and the shorter treatment duration as well as the less complication of SFA [56].

It is necessary for doctors, however, to control the inclusion criteria of SFA strictly. Previous studies enrolled patients with skeletal Class III malocclusion with a flat curve of Spee who were randomized to two independent groups, while a number of patients with these characteristics were not identified by doctors [22]. In spite of the accelerating phenomenon in SFA, there were still several patients failing to finish the whole treatment in 2 years [39]. It is reported that patients treated by SFA had lower compliance at the metaphase of treatment, which might be due to the fact that their worst trouble, the facial deformity, had been solved by the surgery at the beginning, while braces and other devices such as micro-implant anchorage became an annoyance in their lives during the treatment [57]. Therefore, the treatment duration of SFA may not match the expected results.

There were some limitations in our systematic review and meta-analysis. Four studies were included in this systematic review, and totally three of these studies were included in the meta-analysis. However, only two studies were included in each forest plot, which might bias the summary results. In addition, there was only one RCT included eventually. Therefore, multi-center prospective randomized clinical trials with large sample size are needed to confirm the results in our systematic review and meta-analysis. Furthermore, the studies included did not analyse the impact of gender, socioeconomic factors, and individual behavior on the OHRQoL of the patients treated with SFA or CTM, which remains to be researched in further studies.

\section{Conclusion}

This systematic review and meta-analysis showed that current evidence supported the better OHRQoL outcomes of patients treated by SFA than CTM. However, there was only one RCT included eventually. The limited numbers of enrolled participants tent to increase the bias as well. Large sample and well-designed RCTs are needed to validate and confirm the results in this meta-analysis in future.

\section{Abbreviations}

CCTs: Controlled clinical trials; CTM: Conventional three-stage method; OHIP14: 14-item Oral Health Impact Profile; OHRQoL: Oral health-related quality of life; OQLQ: Orthognathic Quality of Life Questionnaire; RCTs: Randomized controlled trials; SFA: Surgery first approach

\section{Acknowledgements \\ None.}

\section{Authors' contributions}

$\mathrm{XH}$ and $\mathrm{XC}$ conducted the literature search, $\mathrm{XH}, \mathrm{WS}, \mathrm{KX}$ and LY performed the statistical analysis and draft the manuscript. $J$ and $Z Z$ designed the study and revised the manuscript. All authors read and approved the final version of submission.

\section{Funding}

This study was supported by grants from the National Natural Science Foundation of China (81771048, 81870743 and 81470722) and the Creative Spark Fund of Sichuan University (2018SCUH0007).

Availability of data and materials

The summary of data extraction in this study is available upon request to the corresponding author.

Ethics approval and consent to participate

Not applicable.

Consent for publication

Not applicable.

\section{Competing interests}

The authors declare that they have no competing interests.

\section{Author details}

${ }^{1}$ State Key Laboratory of Oral Diseases \& National Clinical Research Center for Oral Diseases, West China Hospital of Stomatology, Sichuan University, No. 14, 3rd Section, South Renmin Road, Chengdu 610041, Sichuan, China. ${ }^{2}$ Department of Orthodontics, West China Hospital of Stomatology, Sichuan University, Chengdu 610041, People's Republic of China. ${ }^{3}$ Department of Temporomandibular joint, West China Hospital of Stomatology, Sichuan University, Chengdu 610041, People's Republic of China.

Received: 1 March 2019 Accepted: 1 July 2019

Published online: 08 July 2019

\section{References}

1. Sischo L, Broder HL. Oral health-related quality of life: what, why, how, and future implications. J Dent Res. 2011;90(11):1264-70.

2. Pattussi MP, Olinto MT, Hardy R, Sheiham A. Clinical, social and psychosocial factors associated with self-rated oral health in Brazilian adolescents. Community Dent Oral Epidemiol. 2007;35(5):377-86.

3. Palomares NB, Celeste RK, Miguel JA. Impact of orthosurgical treatment phases on oral health-related quality of life. Am J Orthod Dentofac Orthop. 2016;149(2):171-81.

4. Mohamed S, Vettore MV. Oral clinical status and oral health-related quality of life: is socioeconomic position a mediator or a moderator? Int Dent J. 2019;69(2):119-29. 
5. Kiyak HA, West RA, Hohl T, Mcneill RW. The psychological impact of orthognathic surgery: a 9-month follow-up. Am J Orthod. 1982;81(5):404-12

6. Shenoy RP, Shenoy-Panchmal G. Dentofacial disharmonies among adolescents: a study on the prevalence and severity. J Clin Exp Dent. 2015;7(2):e273-7.

7. Lee S, Mcgrath C, Samman N. Quality of life in patients with dentofacial deformity: a comparison of measurement approaches. Int J Oral Maxillofac Surg. 2007;36(6):488-92.

8. Rankin M, Borah GL. Perceived functional impact of abnormal facial appearance. Plast Reconstr Surg. 2003;111(7):2147-8.

9. Alanko OM, Svedströmoristo AL, Tuomisto MT. Patients' perceptions of orthognathic treatment, well-being, and psychological or psychiatric status: a systematic review. Acta Odontol Scand. 2010;68(5):249-60.

10. Group W. Study protocol for the World Health Organization project to develop a quality of life assessment instrument (WHOQOL). Qual Life Res. 1993;2(2):153-9.

11. Proffit WR, Turvey TA, Phillips C. Orthognathic surgery: a hierarchy of stability. Int J Adult Orthodon Orthognath Surg. 1996;11(3):191-204.

12. Tompach PC, Wheeler JJ, Fridrich KL. Orthodontic considerations in orthognathic surgery. Int J Adult Orthodon Orthognath Surg. 1995;10:97-107.

13. Leelasinjaroen P, Godfrey K, Manosudprasit M, Wangsrimongkol T, Surakunprapha P, Pisek P. Surgery first orthognathic approach for skeletal class III malocclusion corrections--a literature review. J Med Assoc Thail. 2012;11(95 Suppl 11):172-80.

14. Wang YC, Ko EW, Huang CS, Chen YR, Takano YT. Comparison of transverse dimensional changes in surgical skeletal class III patients with and without presurgical orthodontics. J Oral Maxillofac Surg. 2010;68(8):1807-12.

15. Profitt WR, White RP Jr. Combining surgery and orthodontics. In: Profitt WR, White Jr RP, Sarver DM, editors. Contemporary treatment of Dentofacial deformity. MO, Mosby: St Louis; 2003. p. 245-67.

16. Jacobs JD, Sinclair PM. Principles of orthodontic mechanics in orthognathic surgery cases. Am J Orthod. 1983;84(5):399-407.

17. Esperão PT, de Oliveira BH, Ma DOA, Kiyak HA, Miguel JA. Oral healthrelated quality of life in orthognathic surgery patients. Am J Orthod Dentofac Orthop. 2010;137(6):790-5.

18. Behrman SJ, Behrman DA. Oral surgeons' considerations in surgical orthodontic treatment. Dent Clin N Am. 1988;32(3):481-507.

19. Liou EJW, Chen PH, Wang YC, Yu CC, Huang CS, Chen YR. Surgery-first accelerated orthognathic surgery: postoperative rapid orthodontic tooth movement. J Oral Maxillofac Surg. 2011;69(3):781-5.

20. Brachvogel P, Berten JL, Hausamen JE. Surgery before orthodontic treatment: a concept for timing the combined therapy of skeletal dysgnathias. Dtsch Zahn Mund Kieferheilkd Zentralbl. 1991;79(7):557-63.

21. Polido W, Faber J, Rocha RS, Fronza B, Marini E. Anticipated benefit: a new protocol for orthognathic surgery treatment that eliminates the need for conventional orthodontic preparation. Dental Press J Orthod. 2011;40(10):1204.

22. Baek SH, Ahn HW, Kwon YH, Choi JY. Surgery-first approach in skeletal class III malocclusion treated with 2-jaw surgery: evaluation of surgical movement and postoperative orthodontic treatment. J Craniofac Surg. 2010;21(2):332-8.

23. Hernández-Alfaro F, Guijarro-Martínez R, Molina-Coral A, Badía-Escriche C. "Surgery first" in Bimaxillary orthognathic surgery. J Oral Maxillofac Surg. 2011;69(6):201-7.

24. Hernández-Alfaro F, Guijarro-Martínez R, Peiró-Guijarro MA. Surgery first in orthognathic surgery: what have we learned? A comprehensive workflow based on 45 consecutive cases. J Oral Maxillofac Surg. 2014;72(2):376-90.

25. Choi SH, Hwang CJ, Baik HS, Jung YS, Lee KJ. Stability of pre-orthodontic orthognathic surgery using intraoral vertical ramus osteotomy versus conventional treatment. J Oral Maxillofac Surg. 2016;74(3):610.

26. Ko EW, Hsu SS, Hsieh HY, Wang YC, Huang CS, Chen YR. Comparison of progressive cephalometric changes and postsurgical stability of skeletal class III correction with and without presurgical orthodontic treatment. J Oral Maxillofac Surg. 2011;69(5):1469-77.

27. Huang CS, Hsu SS, Chen YR. Systematic review of the surgery-first approach in orthognathic surgery. Biom J. 2014;37(4):184-90.

28. Pelo S, Saponaro G, Patini R, Staderini E, Giordano A, Gasparini G, et al. Risks in surgery-first orthognathic approach: complications of segmental osteotomies of the jaws. A systematic review. Eur Rev Med Pharmacol Sci. 2017;21(1):4-12.
29. Yang L, Xiao YD, Liang YJ, Wang X, Li JY, Liao GQ. Does the surgeryfirst approach produce better outcomes in orthognathic surgery? A systematic review and meta-analysis. J Oral Maxillofac Surg. 2017:75(11):2422-9.

30. Peiro-Guijarro MA, Guijarro-Martinez R, Hernandez-Alfaro F. Surgery first in orthognathic surgery: a systematic review of the literature. Am J Orthod Dentofac Orthop. 2016;149(4):448-62.

31. Higgins PT, Green S. Cochrane handbook for systematic reviews of interventions version 5.0.1. Chichester: Wiley Ltd; 2008. pp. 547-58.

32. Wells GA, Shea B, OConnell D, Peterson J, Welch V, Losos M, et al. The Newcastle-Ottawa scale (NOS) for assessing the quality of nonrandomized studies in meta-analyses. Ottawa Hosp Res Instit. 2013;3:1-4.

33. Guyatt GH, Oxman AD, Vist GE, Kunz R, Falck-Ytter Y, Alonso-Coello P, et al. GRADE: an emerging consensus on rating quality of evidence and strength of recommendations. BMJ. 2008:336(7650):924-6.

34. Deeks JJ, Higgins JPT, Altman DG. Chapter 9: Analysing data and undertaking meta-analyses. In: Higgins JPT, Green S. Cochrane handbook for systematic reviews of interventions. Version 5.1.0. Chichester: Wiley; 2011.

35. Deeks JJ, Higgins JPT, Altman DG. Heterogeneity. In: Higgins JPT, Green S, editors. Cochrane handbook for systematic review of interventions. Chichester: Wiley; 2011. p. 228-31.

36. Deeks JJ, Higgins JPT, Altman DG. Summarizing effects across studies. In: Higgins JPT, Green S, editors. Cochrane handbook for systematic review of interventions. Chichester: Wiley; 2011. p. 217-27.

37. Park JK, Choi JY, Yang $\mathrm{H}$, Baek SH. Patient's satisfaction in skeletal class III cases treated with two-jaw surgery using orthognathic quality of life questionnaire: conventional three-stage method versus surgery-first approach. J Craniofac Surg. 2015;26:2086-93.

38. Huang S, Chen W, Ni Z, Zhou Y. The changes of oral health-related quality of life and satisfaction after surgery-first orthognathic approach: a longitudinal prospective study. Head Face Med. 2016;12:1-7.

39. Feu D, de Oliveira BH, Palomares NB, Celeste RK, Jam M. Oral health-related quality of life changes in patients with severe class III malocclusion treated with the 2-jaw surgery-first approach. Am J Orthod Dentofac Orthop. 2017;151(6):1048.

40. Pelo S, Gasparini G, Garagiola U, Cordaro M, Di Nardo F, Staderini E, et al. Surgery-first orthognathic approach vs traditional orthognathic approach: Oral health-related quality of life assessed with 2 questionnaires. Am J Orthod Dentofac Orthop. 2017;152:250-4.

41. Slade GD. Derivation and validation of a short-form oral health impact profile. Community Dent Oral Epidemiol. 1997;25:284-90.

42. Miguel JA, Palomares NB, Feu D. Life-quality of orthognathic surgery patients: the search for an integral diagnosis. Dental Press J Orthod. 2014;19: 123-37.

43. Koller M, Lorenz W. Quality of life: a deconstruction for clinicians. J R Soc Med. 2002;95:481-8.

44. Montero J, López JF, Vicente MP, Galindo MP, Albaladejo A, Bravo M. Comparative validity of the OIDP and OHIP-14 in describing the impact of oral health on quality of life in a cross-sectional study performed in Spanish adults. Med Oral Patol Oral Cir Bucal. 2011;16(6):816-21.

45. Larsson P, List T, Lundström I, Marcusson A, Ohrbach R. Reliability and validity of a Swedish version of the Oral health impact profile (OHIP-S). Acta Odontol Scand. 2004;62(3):147-52.

46. He SL, Wang JH. Reliability and validity of a Chinese version of the Oral health impact profile for edentulous subjects. Qual Life Res. 2015;24(4):1011-6.

47. Kilinc A, Ertas U. An assessment of the quality of life of patients with Class III deformities treated with orthognathic surgery. J Oral Maxillofac Surg. 2015;73:1394.e1-5.

48. Rustemeyer J, Martin A, Gregersen J. Changes in quality of life and their relation to cephalometric changes in orthognathic surgery patients. Angle Orthod. 2012:82(2):235-41.

49. Tachiki C, Nishii Y, Takaki T, Sueishi K. Condition-specific quality of life assessment at each stage of class III surgical orthodontic treatment - a prospective study. Bull Tokyo Dent Coll. 2018;59(1):1-14.

50. Elmouden L, Ousehal L. Assessment of the quality of life in Moroccan patients undergoing orthognathic surgery. Turk J Orthod. 2018;31(3):79-85

51. Gabardo MC, Moysés ST, Moysés SJ. Self-rating of Oral health according to the Oral health impact profile and associated factors: a systematic review. Rev Panam Salud Publica. 2013;33(6):439-45. 
52. Khadka A, Liu Y, Li J, Zhu S, Luo E, Feng G, et al. Changes in quality of life after orthognathic surgery: a comparison based on the involvement of the occlusion. Oral Surg Oral Med Oral Pathol Oral Radiol Endod. 2011;112:719-25.

53. Bortoluzzi MC, Manfro R, Soares IC, Presta AA. Cross-cultural adaptation of the orthognathic quality of life questionnaire (OQLQ) in a Brazilian sample of patients with dentofacial deformities. Med Oral Patol Oral Cir Bucal. 2011;16:694-9.

54. Chapman JA, Roberts WE, Eckert GJ, Kula KS, González-Cabezas C. Risk factors for incidence and severity of white spot lesions during treatment with fixed orthodontic appliances. Am J Orthod Dentofac Orthop. 2010;138(2):188-94.

55. Verrusio C, lorio-Siciliano V, Blasi A, Leuci S, Adamo D, Nicolò M. The effect of orthodontic treatment on periodontal tissue inflammation. A systematic review. 2018;49(1):69-77.

56. Min BK, Choi JY, Baek SH. Comparison of treatment duration between conventional three-stage method and surgery-first approach in patients with skeletal class III malocclusion. J Craniofac Surg. 2014;25(2):1752-6.

57. Kiyak HA, Hohl T, West RA, McNeill RW. Psychological changes in orthognathic surgery patients: a 24-month follow up. J Oral Maxillofac Surg. 1984;42:506-12.

\section{Publisher's Note}

Springer Nature remains neutral with regard to jurisdictional claims in published maps and institutional affiliations.

Ready to submit your research? Choose BMC and benefit from:

- fast, convenient online submission

- thorough peer review by experienced researchers in your field

- rapid publication on acceptance

- support for research data, including large and complex data types

- gold Open Access which fosters wider collaboration and increased citations

- maximum visibility for your research: over $100 \mathrm{M}$ website views per year

At $\mathrm{BMC}$, research is always in progress.

Learn more biomedcentral.com/submissions 